\title{
Life Cycle Analysis of Computer Numerical Control (CNC) Machine Components
}

\author{
Moriarty Kevin \\ Mechanical and Industrial Engineering, New Jersey Institute of Technology, Newark, the United Sates \\ Email address: \\ kmm65@njit.edu \\ To cite this article: \\ Moriarty Kevin. Life Cycle Analysis of Computer Numerical Control (CNC) Machine Components. American Journal of Computer Science \\ and Technology. Vol. 4, No. 1, 2021, pp. 11-18. doi: 10.11648/j.ajcst.20210401.12
}

Received: February 6, 2021; Accepted: February 24, 2021; Published: March 4, 2021

\begin{abstract}
The nucleus of this concept and system is directly focused on a 'computer numerical control' (CNC) turret lathe and milling machine tool systems. These concepts focus specifically to this category of engineered systems. Quality design review for quality service systems is a unique concept. Standard product service systems are qualitative and subjective in nature. A quantitative system identifies Key Predictive Attributes (KPA's), which identifies a new concept application technique and applies quantitative methods to these attributes to develop a systemic process of analyzing and monitoring the system. This research is reviewing the specific projection of service outcomes for Machine tool CNC machining centers (Lathes and Milling Machines). The specific key predictive attributes are the elements being utilized in the newly created modular function in this research, to assess the potential impact of discrete elements of these attributes as it affects the occurrence of equipment down time for a system which will work to quantify the service quality of the maintenance process. This project is unique in that currently there is no system which utilizes methods or tools, that proactively gather, analyze, assess, and project outcomes of equipment "Down Time" of the Service Quality process. The innovative position of this analysis is one of actual variable tolerances, versus a more traditional nominal referenced variable reference. What makes this research unique additionally is the system is pre-service and not post service reporting of actual down time of the equipment. This research is much more than pro-forma estimate of service outcomes. Another unique aspect of this method is that it will establish tangible tolerances to assess the performance of the Design Review and Service Quality process and not just rely on subjective nominal values. Mathematical Upper Control Limits (UCL) and Lower Control Limits (LCL) will be programmatically developed based upon the system data. This system tool will develop programming algorithms which will propel this current process from a subjective qualitative process to become a robust quantitative projection tool. The novelty in this research is the development of a quality index through the creation of the new Moriarty/Ranky Transform approach.
\end{abstract}

Keywords: CNC, Quality Service, Maintenance, Life Cycle, Predictive Attributes

\section{Introduction}

The purpose of this research article is to present a set of quantifiable measures for the prediction and performance of quality maintenance of $\mathrm{CNC}$ manufacturing equipment for improving productivity and reduce machine down time due to unscheduled and scheduled maintenance functions that can be applied to this equipment. In this article, the analysis is a unique methodology presented as applied to the quantifiable analysis in terms of major "Key Predictive Attributes" (KPA) aspects. A comprehensive component life cycle analysis, cost factor reviews over the equipment's four steps of product life cycle: Material \& Supplier, Manufacture
Production/Assembly, Use/Operation (which is not component of this research study), Quantified Service Quality Maintenance and End of Life (EoL) steps. Material types include: (e.g., steel, aluminum, titanium, and composites, etc.), manufacture process (casting, forging, removal (machining) and/or additive (3D printing) manufacturing and assembly methods (manual, semi \& automated and/or robotic). A quantifiable scoring method Moriarty / Ranky Transform (M/R T algorithm) has been developed and used to decide how certain attribute factors affect the prediction of maintenance outcomes using these scenarios. The factor categorized into two groups: operational, and technical groups. Each group has analogous features which are (or may be) utilized, so only 
important KPA's would be selected in the application of this report. The actual dissertation proceeds to develop and validate scoring methods to get a better understanding of the relative $\mathrm{M} / \mathrm{R}$ T ranking for different maintenance applications circumstances. This work examines the application and role of multi-criteria activities and methods in assessing and predicting the outcome of projected maintenance functions and activities.

Materials selection methods include quality function deployment (QFD) and analytical hierarchy process (AHP) [4, 18]. The addition of multi-criteria variable selection methods are tools which assist in the choice of alternatives, particularly when conflicting goals exist $[19,20]$. And then the use and or creation of a knowledge-based system (KBS) to establish the computer resource technology and means of managing the quality service modeling process $[21,22]$. The goal behind using KBS is to help designers, service managers, technicians and machine operators establishing the KPA data and generation of the Predictive Quality Service System (PQSS) index value for associated with necessary equipment service.

There are numerous researchers today exploring new methods in CNC machine control to monitor and improve quality of machined parts. Many prediction models based on empirical methods are used to analyze the relationships between machining parameters and part quality. Practical data has been identified for further development of optimizing machine control, and many have been built upon Artificial Intelligence (AI) algorithms [16]; An example of this empirical approach using AI as a prediction model for material condition was developed [16], which intended to optimize machining conditions by minimizing the machine forces thereby improving part condition quality.

While there has been a great deal of research done on many aspects of $\mathrm{CNC}$ machine control and productivity interruptions, none have addressed the down time in product return issues, they have not addressed a quantitative, prognostic, predictive method to improve the service provider's performance. Previous research verifies Adaptive Control (AC) has been introduced as an effective method of optimizing machining parameters in the past $[11,12]$. More recently, the implementation of fuzzy logic models for predicting and controlling part condition has been investigated and implemented as a method of improving the machined part quality of key components of the machine. Continued productivity of $\mathrm{CNC}$ machines can be monitored through the ability to model process down time risk. The incorporation of fuzzy logic controllers to assist in controlling and predicting part quality has increased in popularity [24].

Within the new age of Smart Manufacturing and Industry 4.0, product life cycle management (PLM) and prognostic health management (PHM), a key connection must exist between these and data management systems, [26]. Xia T, Dong Y, Xiao L, Du S, Pan E, Xi L., 2018]. Within several applications of 3D printing (additive manufacturing) there has been extensive development and support for PLM and PHM [10].

This research addresses the next generation of service maintenance, which is a new and unique approach developed as Quantifiable Service Quality. The focus is on the preliminary materials suppliers, manufacturing /production/assembly method, Quantifiable Service Quality maintenance, and EoL analysis. The combination of the material selection principles with decision making methods are a means of developing multi-attribute material selection methods instead of utilizing only one objective at a time [9, 17]. Consider a machine contains " $n$ " number of parts, each component has " $\mathrm{m}$ " material options, each material there are "s" supplier, "p" production methods, "a" assembly processes, and finally for each of these material options " $\mathrm{e}^{\prime \prime}$ EoL possibilities exist, Therefore, $m^{n} \times s^{n} x p^{n} x a^{n} x e^{n}$ solutions are possible. As a result, the objective of the life cycle analysis cost estimation is to minimize the service cost and the production impact (its productivity impact) throughout the equipment product life cycle.

The overall objectives are to minimize the service costs and productivity interruptions through quantifiable service quality system methods and equipment life cycle management. This model is designed to assess different issues simultaneously: namely: material alternative selection, supplier selection, manufacturing and assembling process selection as well as the actual service functions and equipment EoL options.

Therefore, the M/R T algorithm can be used for solving multiple causes simultaneously e.g.: component alternatives, supplier selection, production and assembly processes and service options and the EoL option determination of the equipment.

\section{Classification Models}

The use of classification models of optimal part/service configuration selection assessment is difficult and quite time-consuming. It is impossible to solve this multitude of configurations in consideration of the magnitude of design alternatives to achieve an optimal configuration. In this document an original quantitative services quality evaluation method creates a service index value, which takes quality functional development to the next level derived from the multi objective optimization model developed to assist with the selection of the optimal combination of supplier, material, production, and assembly methods in the shortest possible time.

a) Multi-criteria decision-making approaches and

b) Multi-objective decision making and

c) Life-cycle analysis methods

Life cycle analysis (LCA) methods have developed comprehensive frameworks configurations to select sustainable life cycle assessment perspectives [13, 25]. To conduct an LCA, data and information needs to be collected for analysis, of the cumulative components and services to the end-of-life equipment. Therefore, the implementation of an LCA, due to the complexity and diversity of components and the time frame produces a high number of inputs and outputs to the system which is very costly, time consuming and difficult task [1]. Multi-criteria decision-making methods [13, $14,15]$ can develop a variety of methods to apply 
sustainability considerations with a lifecycle approach for choosing materials and methods of manufacture of the components under review and assessed.

This proposed model uses a cohesive mixed method considering issues simultaneously: component selection, service provided and the EoL options similar to the gray-relational-analysis method, where the choice of the optimal option is in terms of economic, technical, and aspects [6-8, 27].

\section{Model Formulation}

\subsection{Supply and Distribution}

1. Stock

2. Warehouse next day

3. Order

a. Short term (3-5 days)

\section{b. Long term (7-30 days)}

4. Need to Manufacture (special order)

\subsection{Main Concepts}

The Main Components of the Model Material Type and Fabrication Method, Source/Supply, and Assembly Methods, Then Finally the EoL Decision Process and Options

Materials

1. Metal:

Ferrous

Nonferrous

2. Plastic

3. Ceramic

Each product, has lifecycle steps and each step is depicted in Figure 1.

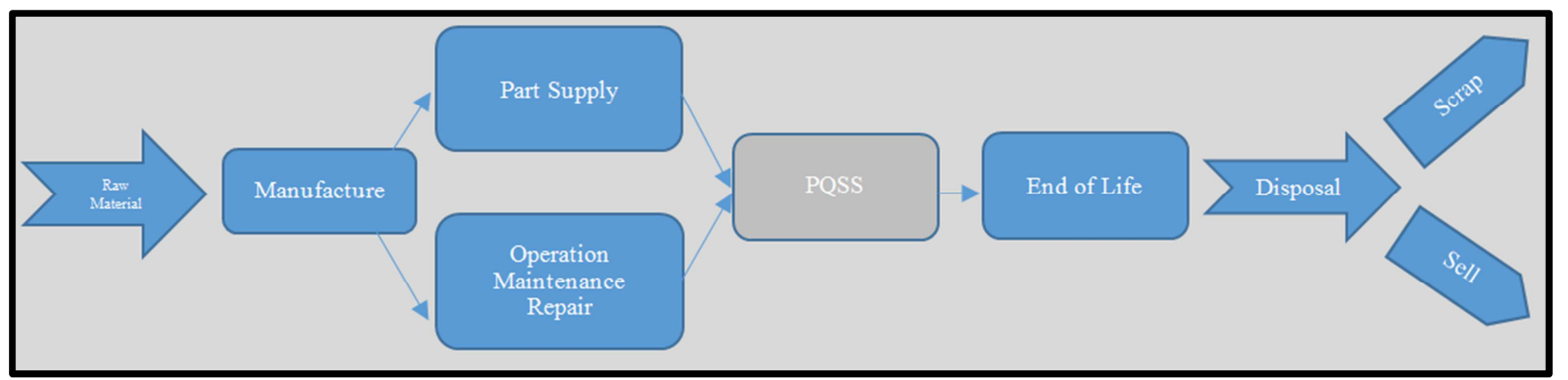

Figure 1. Life cycle steps through quality service.

\subsection{Production Process Is the Method of Fabrication of the Specified Components}
1. Machining
2. Casting
3. $3 \mathrm{D}$ printing
4. other

\subsection{Assembly Service Process}

1. Manual mechanical

2. Manual electronic

3. Software digital

\subsection{End of Life}

1. Repair

2. Limited use

3. Remanufacturing

4. Disposal

Sell: used as is

Scrap: Disassembly, Recycle

Therefore, simultaneous reviews of the steps of machine lifecycle for the determination of the level of service is essential. In each step, several factors that strongly influence the performance outcome of type of service conducted. The factors considered in each Step respectively are: suppliers, manufacturing, assembly processes and EoL options. The end-of-life step is an important component of equipment life cycle, which is of great interest to many researchers in the area of critical equipment maintenance. End-of-life equipment/machines have a high potential for failure.

In addition, many of these products have large physical dimensions, if not repaired for continued use this space impacts operational resources and not available for productive purposes which then impacts performance.

Sets

$B$ The set of components, index by $i,|B|=n$

$G$ Number of product life cycle steps, index by $g, g=1 \ldots 4$

$M_{i}$ The set of possible material choices for component $i$, index by $j,\left|M_{i}\right|=m_{i}, i<-N$

$P_{i j}$ The provider of material $j$ for component $i$, index by $u$, $\left|P_{i}\right| j=p_{i j}, i<-N, j<-M_{i}$

$C_{i j}$ The set of components $i$, for material $j$, index by $t,\left|C_{i}\right| j$ $=\mathrm{c}_{i j}, i<-N, j<-M i$

$E_{i j}$ The set of EoL possibilities for component $i$, under material $j$, index by $k$,

$$
\left|E_{i j}\right|=e_{i j}, i<-N, \mathrm{j}<-M_{i}
$$

$\mathrm{R}_{i j ; i^{\prime} j^{\prime}}$ The processes attributes $(\mathrm{M} / \mathrm{R} \mathrm{T})$ for the service and assembly of components $i$ material $j$, along with the component $i^{\prime}$ of material $j^{\prime}$, index by $a,\left|R_{i j} ; i^{\prime} j^{\prime}\right|=h_{i j ;} i^{\prime} j^{\prime}, i<N, j$ $<M i, i,<N, j<M_{i}^{\prime}$

$Q_{i}$ The set of expected performance of service provided from PQSS program $i$, index by $b,\left|Q_{i}\right|=q_{i}, i 2 \mathrm{~N}$.

Decision variable: binary variables which will equal 0 or 1 respectively.

$x_{i j}$ if the material $j$ is chosen for component $i$, variable 
equals 1 ; otherwise, it equals 0 for this.

$y_{i j u}$ if supplier $u$ is chosen to supply $j$ for component $\mathrm{i}$, variable equals 1 otherwise it equals 0 .

$w_{i j t}$ if manufacturing process $t$ is chosen to produce component $i$ of material $j$ variable equals 1 ; otherwise, it equals 0 .

$q_{i j ; i^{\prime} j^{\prime} ; a}$ if the assembly process $a$ is used to assemble the component $i$ of material $j$ to the component $i^{\prime}$ of material $j$; the variable equals 1 otherwise it equals 0 .

$z_{i j k}$ if EoL option $k$ is chosen for component $i$ of material $j$, the variable equals 1 , otherwise it equals 0 .

Parameters

$C^{T}$ Total product cost over its life cycle

$C_{g}$ Total product cost at step $g$

$C^{P} i j u$ The cost of purchasing material $j$ from the provider $u$ to produce component $i$.

$d_{i j u}$ The distance of supplier $u$ from manufacturer to supply material $j$ for component $i$

$C^{M}{ }_{i j t}$ The production cost of component $i$ from material $j$ by manufacturing process $t$.

$C^{A}{ }_{i j ; i j^{\prime} ; \text {; } a}$ The cost of assembling component $i$ of material $j$ along with the component $i^{\prime}$ of material $j^{\prime}$

by assembly process $a_{-} i ; i^{\prime}$ If component $i$ is assembled into $i^{\prime}$, the value is one or otherwise it will be zero.

The machine lifetime usage (hours)

$C^{R}{ }_{i j}$ The replacement cost of component $i$ from material $j \_i j$ the maintenance and repair frequency of component $i$ from material $j$ during a product life cycle

$\Omega$ The EoL cost

$C^{D}{ }_{i j ; i^{\prime} j^{\prime} ; a}$ The cost of disassembling component $i$ of material $j$ from component $i^{\prime}$ of material $j^{\prime}$ if they are assembled by $a$ process.

$C^{O}{ }_{i j k}$ The EoL cost if method $k$ is used for component $i$ from material $j$.

$\omega i$ The performance score of component $i$

$\vartheta b i$ The importance of performance $b$ in component $i$

$l$ bij The performance score $b$ in component $i$ if material $j$ use

$\lambda i$ Minimum acceptable performance for component $i$

$\mu i$ The importance of component $i$ in the product

$\xi i$ The Performance Score of total Product

$\tau$ Minimum acceptable performance for product.

$\psi i ; j$ A set of material alternatives that are must be selected at the same time with the alternative $j$ of component $i . j i ; j=I^{\prime}$; j'

$$
\sum_{\mathrm{i}=1}^{n} \sum_{\mathrm{j}=1}^{m_{i}} \sum_{\mathrm{u}=1}^{p_{i j}} y_{i j u}\left(C_{i j u}^{P}+d_{i j u} \cdot C_{i j u}^{T} \cdot W_{i j}\right) \cdot \eta_{i j}+\sum_{\mathrm{i}=1}^{n} \sum_{\mathrm{j}=1}^{m_{i}} \sum_{\mathrm{u}=1}^{p_{i j}} W_{i j t} \cdot C_{i j t}^{M}+\eta_{i j u}+\sum_{\mathrm{i}=1}^{n} \sum_{\mathrm{j}=1}^{m_{i j}} \chi_{i j t} \cdot C_{i j}^{R} \cdot \eta_{i j}+\Omega \cdot \eta_{i j}
$$

At this step, there is a cost for maintenance and repairs, and it is assumed that the defective component is replaced with the new one.

According to equation (4) the cost of maintenance and repair is the total cost of material supply, manufacturing process, replacement and EoL.

Therefore, the CNC machine operation cost is equal to Material supply and production process costs and are calculated in accordance with equations 3 and 4 respectively, $\phi i ; j$ A set of material alternatives that are cannot to be selected along with the alternative $j$ of component $i . j \varphi i ; j=\varphi i$; $j^{\prime}$.

\section{Cost Functions and Analysis}

\subsection{Cost Equations}

$$
\min _{g=1}^{B} C_{P}=\Sigma C_{g}, g=1-. B B=1 \ldots 4 \ldots
$$

$C^{P}$ Total product cost over its life cycle, $C^{g}$ Total product cost at Step $g$

First step: The first step is materials provided relating to available suppliers. The selection of a suitable supplier is the decision variable at this step. For Original Equipment Manufacturers (OEM's), regional transportation and delivery lead time are key in the material selection process.

Consequently, the cost at this step is obtained by the following equation (1).

$$
\sum_{\mathrm{i}=1}^{n} \sum_{\mathrm{j}=1}^{m_{i}} \sum_{\mathrm{u}=1}^{S_{i j}} y_{i j u}\left(C_{i j u}^{P}+d_{i j u}+C_{i j u}^{T} W_{i j}\right)
$$

Second step: is manufacturing/assembly process: The decision variable at this Step is manufacturing and assembly process selection.

Equation (2) represents the component cost.

$$
\sum_{\mathrm{i}=1}^{n} \sum_{\mathrm{j}=1}^{m_{i}} \sum_{\mathrm{t}=1}^{p_{i j}} w_{i j u} C_{i j t}^{M}
$$

In addition to the production of components the cost of assembling components into the product should be calculated in accordance with equation (3).

$$
\sum_{\mathrm{i}=1}^{n} \sum_{\mathrm{i}^{\prime}=1}^{i-1} \sum_{\mathrm{j}=1}^{m_{i}} \sum_{\mathrm{j}^{\prime}=1}^{m^{\prime} i} \sum_{\mathrm{a}=1}^{h_{i j, i^{\prime} j^{\prime}}} \alpha_{i j} q_{i j, i^{\prime} j^{\prime}}, \alpha \cdot C_{i j ; i{ }^{\prime} j \prime ; a}^{A}
$$

Third step: operational use, maintenance, and repairs, since the components are not used alone and are assembled together and then the entire CNC machine is used, the costs associated with the use phase should be examined at the product level. In order to assess the cost and impact of this step, first the CNC machine usage should be determined.

According to studies, machine run time has a direct correlation with lifetime span and CNC productivity.

In this study, the runtime... equation (4), its value for the $\mathrm{CNC}$ machine examined in this paper is,

and the replacement cost of the components is calculated according to Equation (5).

$$
\sum_{\mathrm{i}=1}^{n} \sum_{\mathrm{j}=1}^{m_{i}} \chi_{i j t} C_{i j}^{R}
$$

The method for calculating EoL cost will be discussed in the next section, equation (6). Where $\_i j$ is the frequency of maintenance and repair of component $i$ made of material $j$ during the $\mathrm{CNC}$ machine entire life cycle. 


$$
\Omega=\sum_{i=1}^{n} \sum_{j=1}^{m_{i}} \sum_{k=1}^{o_{i j}} w_{i j k} C_{i j k}^{o}
$$

Fourth step: End of life (EoL). The final Step is the management of product EoL, which is an important phase for assessing the service outcomes of CNC equipment / machines. [1].

The EoL options investigated in this study are: repair for use, rebuild / remanufacture, or disposal (scrap/recycle). In order to reach total EoL, the product must be repairable, completely disassembled for rebuild / remanufacture or scrapped/recycled.

Product EoL and disposal costs are calculated by equation (5) and (6) respectively.

$$
\sum_{\mathrm{i}=1}^{n} \sum_{\mathrm{i}^{\prime}=1}^{i-1} \sum_{\mathrm{j}=1}^{m_{i}} \sum_{\mathrm{j}^{\prime}=1}^{m^{\prime} i} \sum_{\mathrm{a}=1}^{h_{i, i t^{\prime}}} \alpha_{i j} \cdot q_{i j, i^{\prime} j^{\prime}}, \alpha \cdot C_{i j ; i j^{\prime} ; a}^{D}
$$

\subsection{The Cost Associated with Assembly, Setup, and Overhead Functions}

This includes element component subassembly variants of part design configuration, and the usage of new, reused, and/or refurbished component parts made from recycled materials and the cost of collecting these parts, may also be considered when assessing EoL products.

Hence, the objective function is shown below [2], Cost objective function.

By summation of the above four mentioned costs, the overall cost function is obtained, and the objective is to minimize the overall cost.

Various other constraints related to raw materials, production methods, resource availability, production capacity, etc., could be relevant, dependent upon the specific product and manufacturer considered during the quantified service optimization configuration process. Such constraints would need to be included on a case-by-case basis when preparing the constraints of the specific situation [3] Solving the multi-objective optimization problem is an evolutionary process and has been utilized in research and many other studies. Algorithms of this nature are capable of reducing computational difficulty and providing an effective method of handling constraints, which makes it an efficient method of solving for multi-objective optimization [5].

\subsection{Design and Management Cost Impacts}

The service cost is reverted to an original cost and added to the cost of the original machine cost and then a percentage of ownership cost is computed. This method is an original means of associating the cost of ownership with the overall cost of the equipment. This is done by calculating the present value equivalent of this cost, the value generated from this service analysis in the research. This present value is based upon a general $3 \%$ cost of inflation (i) over the same time period (lifetime of the equipment $=\mathrm{n}$ ) on an annual basis, e.g., cost value of service analysis * $(1+i)^{\text {service lifetime }}$, cost $(1+.03)^{-\mathrm{n}}$.

This example displays the detailed aspects of this analysis using the following information: the machine installation date of Feb $15^{\text {th }}, 2015$, a maintenance service date of Dec $15^{\text {th }}$,
2019 , an interest rate of $3 \%$, a machine installation price or $\$ 375,000$, and a maintenance cost of $\$ 5,000$. As seen from this analysis.

Added Cost $=\$ 5000(1+0.03)^{-3.9}$

Table 1. Research index value example.

\begin{tabular}{ll}
\hline Description & Value \\
\hline Index Value & 96 \\
Maintenance Cost & $\$ 5000$ \\
\hline
\end{tabular}

Table 2. Analysis.

\begin{tabular}{ll}
\hline Description & Value \\
\hline Percentage or & \\
Installed cost & $1.2 \%$ \\
Present Cost & $\$ 4,455$ \\
Installed date & $2 / 10 / 2015$ \\
Service date & $12 / 18 / 2018$ \\
Interest & $3 \%$ \\
Price & $\$ 375,000$ \\
Maintenance Cost & $\$ 5,000$ \\
\hline
\end{tabular}

\section{Description of the Mathematical Model Constraints}

\subsection{Component Functions}

The performance of each component is multiplied by its importance and the total product function is obtained.

$$
\begin{gathered}
\sum_{\mathrm{b}=1}^{q} \sum_{j=1}^{m_{i}} \chi_{i j} \cdot \vartheta_{i j} \cdot \iota_{b i j}>\lambda_{i j} T_{i} \\
\sum_{i=1}^{n} \mu_{i j} \cdot \omega_{b i j}>\tau \\
\sum_{j=1}^{m_{i}} \chi_{i j}=1 T_{i}, j\left(j<m_{i}\right) \\
\sum_{u=1}^{s_{i j}} Y_{i j u}=\chi_{i j} T_{i}, j\left(j<m_{i}\right) \\
\sum_{t=1}^{p_{i j}} v_{i j t}=\chi_{i j} T_{i}, j\left(j<m_{i}\right) \\
\sum_{k=1}^{o i j} Z_{i j t}=\chi_{i j} T_{i}, j\left(j<m_{i}\right)
\end{gathered}
$$

Constraints 8 to 13 ensure that each selected component is made up of only one material, and has one supplier, one production/assembly process and only one EoL option [1].

\subsection{Solving the Model}

In this research, categories of components investigated: The drive motor of the machine (includes 4 key components), closures and safety controls (6, including main panels), slides, ways, and holding devices (including 6 components) and electronics (8 components), therefore, for purposes of this paper a total of 24 components have be utilized to examine the functional model.

Material alternatives for components in this study are classified into 6 general categories: steels, high strength steels, stainless steel, aluminum, and composites such as: (standard plastics, fiber glass reinforced plastic and carbon fiber-reinforced plastic). 
Material choice can be problematical for an engineer, particularly when the material is being used in an application for the first time. The process of material selection for this research supports the design engineering role during the early and design steps of product development.

For durable material selection, tradeoffs between economic, life cycle, and technical requirements for each component are identified and ranked. In the proposed model, the technical criteria are considered as constraints, as explained in the previous section. A list of some of the major components used in this analysis are shown in the conclusion of this research. The technical criteria and the score of each sub-function is extracted from [13-15] references.

To calculate impacts, performing a comprehensive life cycle assessment is very complex, time-consuming, costly, and requires a wide range of data.

Therefore, in this paper, EoL is used as the measure of the product productivity [1] used as a gauge to quantify the productivity impact of a given data set for $\mathrm{CNC}$ service maintenance.

This developed model is a multi-objective linear model. An increase in the number of components, which increases the alternatives of the materials, will therefore increase the complexity of the model which then increases exponentially. If we assume a machine has only 4 components and for each component there are 3 material alternatives, each of the material alternatives has at least two suppliers, for each material, at two different means of production and assembly are available and each of these alternatives have the four EoL options. Therefore, there will be $3^{4} \times 2^{4} \times 2^{4} \times 4^{4}$ or 5,308,416 alternatives to select. Adding only one component $\left(3^{5} \times 2^{5} \times 2^{5}\right.$ $\mathrm{x} 4^{5}$ ) will increase the number of options to $254,803,968$, This demonstrates the challenge and magnitude of this enormous task of selecting the best configuration. and while the developed model provides CNC machine tool manufacturers, and service providers and maintenance providers the means of selecting optimal alternatives in a reasonably short time period. While there may be no optimal answer to this type of multi-objective problem, a successful (or optimal) pareto solution is are achievable for these problems [23]. A multi-objective decision problem could also be introduced to follow digital -twin approach for product in the smart manufacturing environment [28].

\section{Conclusion}

In this paper, an approach was developed utilizing integer programming to select key alternatives (e.g., material) and optimize CNC machines configuration of components, composed of large number of components. This method of option determination analysis utilizes a number of attributes: material selection, supplier selection, manufacturing process selection, assembly process selection and EoL for components of a CNC machine are integrated and solved simultaneously. The purpose of this model is to minimize producer costs as well as impacts throughout the product life cycle so that the technical and production constraints of the $\mathrm{CNC}$ machine are also considered. In order to validate the proposed model, a simulation study was conducted in on vital CNC machine components identified as significant to the CNC service industry. For this purpose, the following general machine component categories have been investigated, (a total of 25 items):

1. enclosure, doors, and safety controls of the machine (6 components),

2. drive motors (4 main drives),

3 . frame, slides, ways and holding devices ( 6 components)

4. electronics and sensors (8 component),

5. lastly software upgrades.

In addition, sensitivity analysis was conducted to evaluate the effect of $\mathrm{CNC}$ machine run time on impact and cost. The results show that by reducing runtime the impact upon the CNC machine is also reduced, while the total cost increased. Since, in the proposed model, the product runtime rates and technical functions are considered as constraints, the over-reduction of the $\mathrm{CNC}$ machine runtime is in direct conflict with these two constraints and is not feasible; because under use of the $\mathrm{CNC}$ machine significantly reduces the output rate of the machine and does not meet the expected performance and productivity of the research.

\section{Research Innovations}

The concept of reliable component, service and maintenance has concerned maintenance and quality researchers for decades. The development of reliable quality maintenance and production one of the concepts that is a requirement for quantitative tools of measuring and decision making.

While the cost analysis in the example conducted was a sample of just on service incident, the fully functioning simulation uses both individual scenarios of the key components listed as well as the $\mathrm{C}^{\mathrm{T}}$ Cost analysis value to determine the overall cost value and percentage. This value is then converted into a specific "Index Value" (IV) for the specific machine and/or application site. Given an allowable site value between $0.0 \%$ and $\max 30 \%$ for the example e.g., $1.2 \%$ this IV $=96.0$. This index value represents the acceptability score of this service based upon $0-100$ value. Therefore, this example is 96/100 acceptable cost ration $\mathrm{IV}=96.0$.

To achieve this, it is essential to review the methods of selecting key component and service attributes, such as material. The innovation of this methodology of both material selection and quantitative service development approach integrate EoL considerations into the decision process.

The consideration of supplier, manufacturing, assembly process and EoL options variables during the process of optimal selection are key factors.

Reliability, health, and safety requirements in material selection are also key considerations.

Additionally, the consideration of technical requirements in reliability of the key attributes process selection is also fundamental. 
A recommended future direction is to consider the social sustainability attributes in the process of selecting sustainable materials and providing a method for their evaluation. Another interesting future research area is in modelling; consider uncertainty in the proposed mathematical model, may be to use a deterministic model of programming at the appropriate steps in the process. Considering the objective functions of this model versus another optimizing model, could create another kind of problem-solving method in this research field. For example, a goal seek type programming method might be used.

\section{Acknowledgements}

I would like to acknowledge all the assistance received from Paul Ranky, Professor, New Jersey Institute of Technology' Mechanical and Industrial Engineering department who provided insight, vision and expertise assisting with this research that greatly improved the manuscript. I also thank David Ferguson Distinguished Professor, Stony Brook University's College of Engineering and Applied Sciences for his advice and support with this research.

\section{References}

[1] Ameli M, Mansour S, Ahmadi-Javid A (2016), A multi-objective model for selecting design alternatives and end-of-life options under uncertainty: A sustainable approach. Resources, Conservation and Recycling 109: 123-136, DOI 10.1016/j.resconrec.2016.01.011, http://dx.doi.org/10.1016/j.resconrec.2016.01.011.

[2] Aydina, R, Brown A, Badurdeena F, Lia W, Roucha K, I. S. Jawahira, (2018), Quantifying impacts of product return uncertainty on economic and environmental performances of product configuration design, Journal of Manufacturing Systems, 48 (2018) 3-11.

[3] Bi L, Zuo Y, Tao F, Liao TW, Liu Z (2017) Energy- Aware Material Selection for Product with Multicomponent Under Cloud Environment. Journal of Computing and Information Science in Engineering 17 (3): 031007, DOI 10.1115/1.4035675.

[4] Chen SC, Yang CC, Lin WT, Yeh TM, Lin YS. (2007) Construction of key model for knowledge management system using AHP-QFD for semiconductor industry in Taiwan. Journal of Manufacturing Technology Management, 18: 576-598.

[5] Fazleena Badurdeen a, b, Ridvan Aydin a, Adam Brown a, b (2018), A multiple lifecycle-based approach to sustainable product. configuration design, Journal of Cleaner Production 200 (2018) 756e 769.

[6] Govindan K, Madan Shankar K, Kannan D (2015) Sustainable material selection for construction industry - A hybrid multi criteria decision making approach. Renewable and Sustainable Energy Reviews 55: 1274-1288, DOI 10.1016/j.rser.2015.07.100.

[7] Hosseinijou SA, Mansour S, Shirazi MA (2014) Social life cycle assessment for material selection: A case study of building materials. International Journal of Life Cycle $\begin{array}{llll}\text { Assessment } & 19 & \text { (3): } & 620-645,\end{array}$ 10.1007/s11367-013-0658-1.

[8] Jayakrishna K, Vinodh S, Sakthi Sanghvi V, Deepika C (2016) Application of GRA for Sustainable Material Selection and Evaluation Using LCA. Journal of The Institution of Engineers (India): Series C 97 (3): 309, DOI 10.1007/s40032-016-0283-4, URL http://dx.doi.org/10.1007/s40032-016-0283-4.

[9] Jee D-H, Kang K-J. (2000) A method for optimal material selection aided with decision making theory. Materials \& Design, 22: 199-206.

[10] Kaewunruen S, Lian Q.(2018) Digital twin aided sustainability-based lifecycle management for railway turnout systems. Journal of Cleaner Production 2019; 228: 1537-51.

[11] Kucukkoc I, Buyukozkan K, Satoglu SI, Zhang DZ (2015) A mathematical model and artificial bee colony algorithm for the lexicographic bottleneck mixed-model assembly line balancing problem. Journal of Intelligent Manufacturing pp 1-13.

[12] Lim KYH Zheng P, Chen C-H. (2019) A state-of-the-art survey of Digital Twin: techniques, engineering product lifecycle management and business innovation perspectives. Journal of Intelligent Manufacturing 2019: 1-25.

[13] Mayyas A, Shen Q, Mayyas A, Abdelhamid M, Shan D, Qattawi A, Omar M (2011) Using Quality Function Deployment and Analytical Hierarchy Process for material selection of Body-In-White. Materials \& Design 32 (5): 27712782, DOI 10.1016/j.matdes.2011.01.001.

[14] Mayyas A, Qattawi A, Omar M, Shan D (2012a) Design for sustainability in automotive industry: A comprehensive review. Renewable and Sustainable Energy Reviews 16 (4): 18451862 .

[15] Mayyas A, Omar MA, Hayajneh MT (2016) Eco material selection using fuzzy TOPSIS method. International Journal of Sustainable Engineering 9 (5): 292-304, DOI 10.1080/19397038.2016.1153168.

[16] Mia, M., Morshed, M. S., Kharshiduzzaman, M., Razi, M. H., Mostafa, M. R., Rahman, S. M. S., \& Kamal, A. M. (2018). Prediction and optimization of surface roughness in minimum quantity coolant lubrication applied turning of high hardness steel. Measurement: Journal of the International Measurement Confederation, 118, 43-51. https://doi.org/10.1016/j.measurement.2018.01.012.

[17] Rao RV, Davim JP. (2008) A decision-making framework model for material selection using a combined multiple attribute decision-making method. The International Journal of Advanced Manufacturing Technology, 35: 751-760.

[18] Saaty, T. (1990) How to make a decision: The analytic hierarchy process. European Journal of Operational Research, 48 (1): 9-26.

[19] Sapuan S. M. (2001) A knowledge-based system for materials selection in mechanical engineering design. Materials \& Design 22 (8): 687-695.

[20] Sapuan SM, Jacob MSD, Mustapha F, Ismail N. (2002) A prototype knowledge based system for material selection of ceramic matrix composites of automotive engine components. Materials and Design; 23: 701-708. 
[21] Sapuan SM, Abdalla HS. (1998) A prototype knowledge-based system for the material selection of polymeric-based composites for automotive components. Composites Part A: Applied Science and Manufacturing, 29: 731-742.

[22] Shehab E, Abdalla H. (2002) An Intelligent Knowledge-Based System for Product Cost Modelling. International journal of advanced manufacturing technology; 19: 49-65 Sharma S. (1996) Applied multivariate techniques. John Wiley \& Sons, Inc. New York, NY, USA.

[23] Steuer RE, Piercy CA (2005) A regression study of the number of efficient extreme points in multiple objective linear programming. European Journal of Operational Research 162 (2): 484-496.

[24] Volpe Lovato, A., Hora Fontes, C., Embiruçu, M., \& Kalid, R. (2018). A fuzzy modeling approach to optimize control and decision making in conflict management in air traffic control. Computers \& Industrial Engineering, 115, 167-189. https://doi.org/10.1016/j.cie.2017.11.008.

[25] Witik RA, Payet, Michaud V, Ludwig C, E JA (2011) Assessing the life cycle costs and environmental performance of lightweight materials in automobile applications. Composites Part A: Applied Science and Manufacturing 42 (11): 16941709, DOI 10.1016/j.compositesa.2011.07.024, URL http://dx.doi.org/10.1016/j.compositesa.2011.07.024, World Commission on Environment and Development (1987) Our common future. Oxford University Press.

[26] Xia T, Dong Y, Xiao L, Du S, Pan E, Xi L. (2018) Recent advances in prognostics and health management for advanced manufacturing paradigms. Reliability Engineering and System Safety 2018; 178: 255-68.

[27] Zarandi MHF, Mansour S, Hosseinijou SA, Avazbeigi M (2011) A material selection methodology and expert system for sustainable product design. International Journal of Advanced Manufacturing Technology 57 (9-12): 885-903, DOI 10.1007/s00170-011-3362-y.

[28] Zheng P, Sivabalan (2020) AS. A generic tri-model-based approach for product-level digital twin development in a smart manufacturing environment. Robotics and ComputerIntegrated Manufacturing 2020; 64: 101958. 